\title{
PERBANDINGAN LIFE CYCLE COST PERKERASAN KAKU DAN LENTUR (STUDI KASUS: JALAN LINTAS SELATAN JARIT-PUGER STA 25+500-STA 40+400)
}

\author{
TINTANY SWANDARI ${ }^{{ }^{*}}$, AKHMAD HASANUDDIN ${ }^{1}$, WILLY KRISWARDHANA ${ }^{1}$ \\ ${ }^{1} J u r u s a n$ Teknik Sipil, Fakultas Teknik, Universitas Jember. Jember, Jawa Timur, Indonesia \\ *Corresponding author: $ه$ swandari8o@gmail.com
}

Naskah diterima : 19 Januari 021. Disetujui: 31 Juli 2021

\begin{abstract}
ABSTRAK
Pada Desa Wotgalih, Kecamatan Yosowilangun, Kabupaten Lumajang sampai dengan pesisir Pantai Puger, Kabupaten Jember akan direncanakan pembangunan Jalan Lintas Selatan. Jalan ini akan dibangun dari STA 25+500 sampai dengan STA 40+400 dengan nilai CBR pada tanah dasar 22,7\%. Perbedaan penggunaan jenis perkerasan akan menghasilkan nilai life cycle cost yang berbeda pula, nilai life cycle cost yang minimum merupakan salah satu kriteria yang harus dipenuhi dalam merencanakan perkerasan jalan. Menghitung nilai life cycle cost setiap jenis perkerasan bertujuan untuk mendapatkan desain perkerasan yang paling efisien. Dalam merencanakan tebal struktur perkerasan dibutuhkan data sekunder berupa nilai California Bearing Ratio (CBR) dan lalu lintas harian rata-rata. Data-data tersebut diolah sesuai dengan pedoman Manual Desain Perkerasan Jalan 2017. Rancangan anggaran biaya dihitung dengan analisis harga satuan pekerjaan (AHSP) Provinsi Jawa Timur, sehingga didapatkan biaya konstruksi tiap perkerasan. Nilai life cycle cost didapatkan dengan menambahkan biaya konstruksi dan biaya pemeliharaan. Selanjutnya dibutuhkan nilai tingkat inflasi dan nilai suku bunga untuk menghitung nilai discounted life cycle cost. Berdasarkan hasil analisis didapatkan perkerasan lentur terdiri atas lapis pondasi agregat kelas A $130 \mathrm{~mm}, \mathrm{AC}$ Base $115 \mathrm{~mm}, \mathrm{AC}$ BC $60 \mathrm{~mm}$ dan AC WC $40 \mathrm{~mm}$, sedangkan struktur perkerasan kaku terdiri dari lapisan drainase $150 \mathrm{~mm}, \mathrm{LMC} 100 \mathrm{~mm}$, dan pelat beton $195 \mathrm{~mm}$ dengan tie bars diameter $16 \mathrm{~mm}$ dan serta dowel diameter $36 \mathrm{~mm}$. Nilai discounted life cycle cost perkerasan lentur sebesar Rp162.834.408.862 dan perkerasan kaku sebesar Rp64.501.092.789. Perkerasan lentur membutuhkan biaya lebih banyak daripada perkerasan kaku.
\end{abstract}

Kata kunci : perkerasan kaku, perkerasan lentur, manual desain perkerasan, life cycle cost, , present worth

\section{PENDAHULUAN}

Suatu konstruksi jalan befungsi sebagai penghubung satu daerah ke daerah lainnya sehingga dalam jangka panjang diharapkan dapat membangkitkan pertumbuhan sosial dan ekonomi di sekitarnya. Pada Desa Wotgalih, Kecamatan Yosowilangun, Kabupaten Lumajang sampai dengan pesisir Pantai Puger, Kabupaten Jember akan dibangun Jalan Lintas Selatan. Jalan 
ini akan dibangun dari STA 25+500 sampai dengan STA 40+400. Hal ini akan memicu pertumbuhan masyarakat disekitar lokasi pembangunan, maka diperlukan kondisi jalan yang memadai sehingga menimbulkan kelancaran transportasi. Salah satu faktor yang berpengengaruh dalam kelancaran tranportasi yaitu pemilihan perkerasan jalan. Menurut Prayogo Dkk (2018) terdapat beberapa kriteria dalam pemilihan perkerasan jalan diantaranya, kesalamatan dan kenyamanan pengguna jalan, biaya konstruksi, lokasi pekerjaan, pemeliharaan jalan, dan ketahanan terhadap air. Pada penelitian ini membahas lebih detail mengenai biaya konstruksi dalam mempengaruhi pemelihan jenis perkerasan.

Pada Manual Desain Perkerasan Jalan (Dirjen Bina Marga, 2017) dijelaskan nilai life cycle cost yang minimum merupakan satu diantara tolak ukur yang patut dipenuhi dalam tahap perencanaan. Nilai life cycle cost meliputi biaya konstruksi awal dan biaya pemeliharaan di masa yang akan datang. Nurahmi dan Kartika (Nurahmi \& Kartika, 2012) meneliti perbandingan konstruksi perkerasan lentur dan kaku pada proyek pembangunan Jalan Lingkar Mojoagung dengan nilai California Bearing Ratio (CBR) tanah dasar 3,15\% dan didapatkan hasil perkerasan kaku memiliki nilai life cycle cost paling minimum. Lebih lanjut Wahidaturrohmah Dkk (2019) melakukan penelitian serupa pada ruas Jalan Tol GempolPasuruan dengan nilai CBR tanah 1,2\% dan didapatkan hasil perkerasan kaku memiliki nilai life cycle cost paling minimum. Sedangkan pada penelitian Betamal (2015) pada Jalan Batas Kota Bojonegoro-Padangan mendapatkan hasil nilai life cycle cost perkerasan lentur memiliki nilai paling minimum. Lebih lanjut Satria (2016) melakukan penelitian serupa pada ruas Jalan Ajung, Kabupaten Jember dengan nilai CBR tanah dasar 11,50\% dan didapatkan hasil biaya kontruksi perkerasan kaku lebih mahal daripada perkerasan lentur, namun total biaya kontruksi dan pemeliharaan untuk perkerasan kaku lebih murah. Perbedaan ini disebabkan karena volume lalu lintas dan nilai CBR yang berbeda disetiap proyek. Sehingga, nilai life cycle cost setiap jenis perkerasan di setiap proyek tentunya tidak akan sama. Oleh karena itu, pada penelitian ini dihitung tebal dari setiap jenis perkerasan serta membandingkan nilai life cycle cost dari tiap jenis perkerasan, sehingga didapatkan desain perkerasan yang paling efektif dan efisien selama umur rencana.

\section{METODE PENELITIAN}

Lokasi penelitian dilakukan di Jalan Jalur Lintas Selatan Jarit - Puger STA 25+500 - STA 40+400 yang memiliki lebar jalan 7,5 meter dan panjang 14,9 km (Gambar 1). Lebar jalan direncanakan berukuran 7,5 $\mathrm{m}$ dan tipe jalan 2 lajur 2 arah dan tak terbagi atau 2/2 UD.

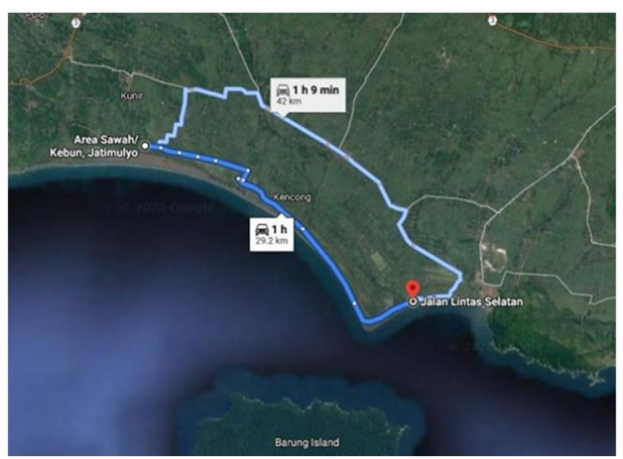

Gambar 1. Lokasi Penelitian

Pada penelitian ini ditahap perencanaan perkerasan jalan kaku dan lentur, digunakan metode manual desain perkerasan tahun 2017. Metode ini dipilih karena merupakan metode terbaru untuk merencanakan pekerasan jalan di Indonesia. Pada metode ini jenis dan tebal 
perkerasan jalan direncanakan berdasarkan beban lalu lintas dan nilai CBR tanah dasar. Untuk perkerasan lentur. Beban lalu lintas didapatkan dari jumlah beban lalu lintas (ESA/Equivalent Standard Axle) setiap sumbu kendaraan. Nilai ESA ${ }^{4}$ digunakan untuk menentukan jenis perkerasan, sedangkan nilai ESA ${ }^{5}$ digunakan untuk menentukan struktur perkerasan lentur. Nilai ESA dapat dihitung dengan rumus berikut.

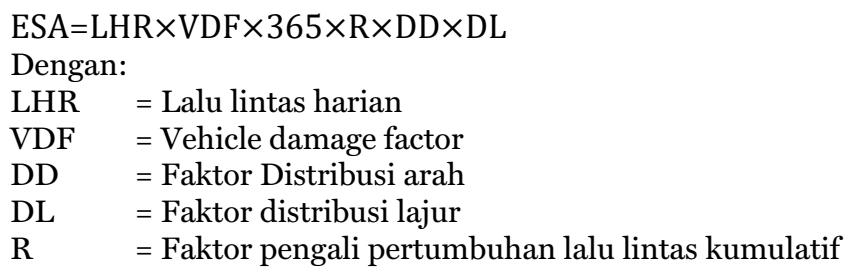

Sedangkan untuk perkerasan kaku beban lalu lintas tidak menggunakan nilai ESA, melainkan menggunakan nilai HVAG (Heavy Vehicle Axle Group) atau kelompok sumbu kendaraan niaga sesuai dengan pedoman Pd-T-14-2003. Nilai jumlah sumbu kendaraan niaga (JSKN) diperoleh dengan rumus berikut.

$\mathrm{JSKN}=365 \times \mathrm{JSKNH} \times \mathrm{R}$

Dengan:

JSKNH = Jumlah sumbu kendaraan niaga harian

$\mathrm{R}=$ = Faktor pengali pertumbuhan lalu lintas kumulatif

Beberapa peneliti telah melakukan perbandingan nilai life cycle cost terhadap konstruksi perkerasan kaku dan lentur. Perbandingan perkerasan kaku dan lentur dipilih karena merupakan jenis perkerasan yang paling umum digunakan di Indonesia. Nurahmi dan Kartika (2012) membandingkan konstruksi perkerasan lentur dan dengan metode benefit cost ratio. Metode ini bertujuan untuk mengevaluasi kelayakan investasi. Benefit adalah saving user cost dan total cost jalan eksisting kondisi normal, sedangkan cost ialah selisih total cost jalan eksisting kondisi normal dengan user cost dan total cost. Lebih lanjut Wahidaturrohman dkk (Wahidaturrohmah et al., 2019) serta Betamal (2015) melakukan penelitian serupa dengan menggunakan metode present worth. Pada metode ini terdapat beberapa variabel yang digunakan, yakni biaya konstruksi awal dan biaya pemeliharaan. Metode ini memproyeksikan semua arus kas pada saat sekarang atau nilai sekarang. Untuk menjawab tujuan penelitian ini, digunakan metode present worth karena cenderung lebih mudah untuk mengukur nilai suatu proyek pada saat sekarang. Hal pertama yang dilakukan yakni menghitung terlebih dahulu dahulu nilai future dari biaya konstruksi dan biaya pemeliharaannya dengan rumus berikut:

$$
F=P(1+i)^{n}
$$

Lalu nilai yang telah difuture kemudian dipresent kembali menggunakan rumus berikut:

$$
\begin{aligned}
& \mathrm{P}=\mathrm{F}=\left[\frac{1}{(1+i)^{n}}\right] \\
& \begin{array}{ll}
\text { Dengan: } & =\text { suku bunga per periode } \\
\mathrm{i}(\text { interest }) & =\text { jumlah periode bunga } \\
\mathrm{n}(\text { number }) & \text { jumlah uang saat ini } \\
\mathrm{P}(\text { present } \text { worth }) & \text { jumlah uang masa depan } \\
\mathrm{F}(\text { future } \text { worth }) & =\text { jumlah }
\end{array}
\end{aligned}
$$

Adapun tahapan analisis data disajikan pada bagan alir di Gambar 2 dibawah ini. 


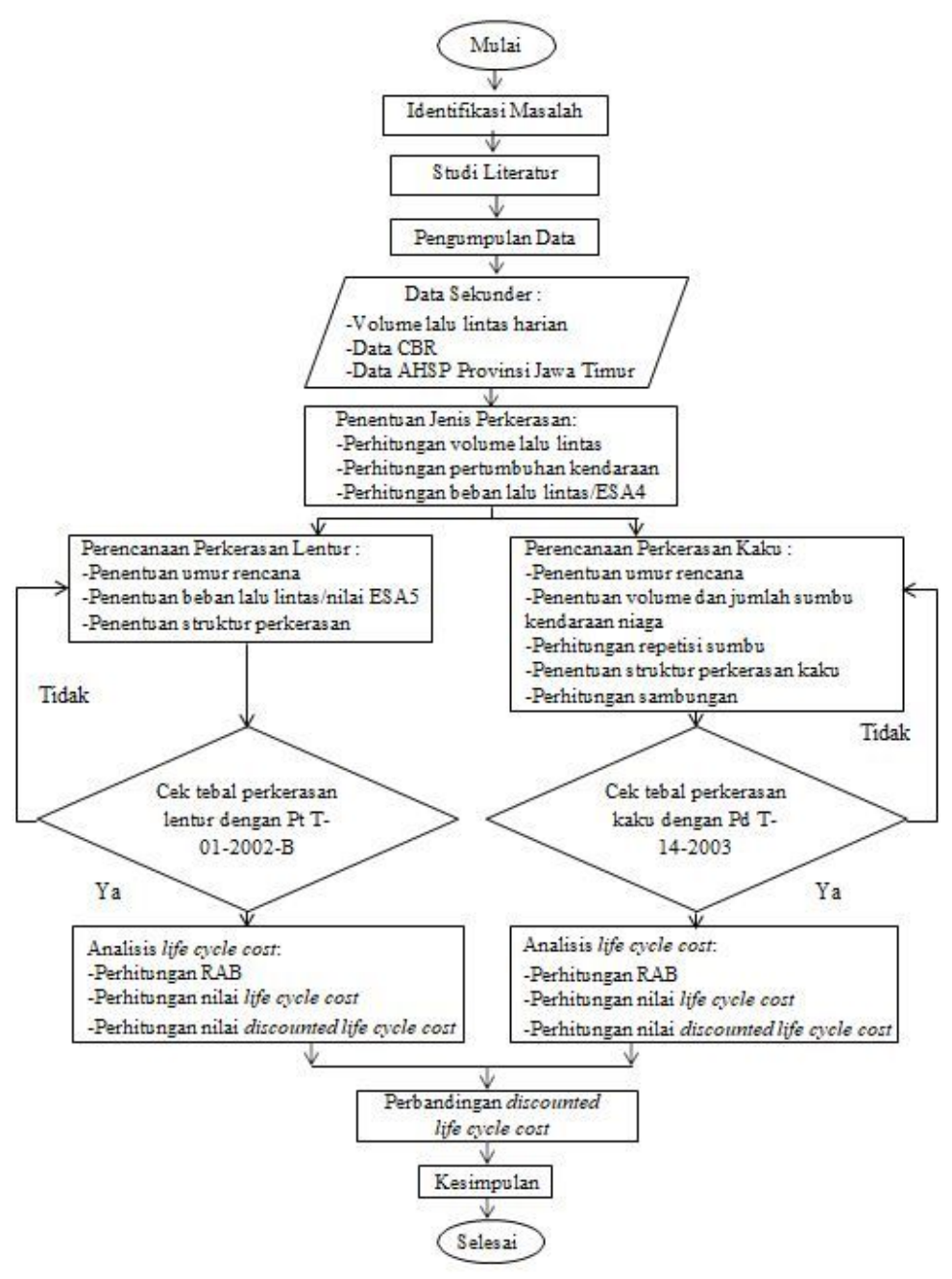

Gambar 2. Bagan Alir Penelitian

\section{HASIL DAN PEMBAHASAN}

\subsection{Nilai CBR Tanah Dasar}

Pengujian ini dilakukan di 94 titik dengan alat Dynamic Cone Penetrometer (DCP). Berdasarkan Manual Desain Perkerasan Jalan (Dirjen Bina Marga, 2017), data CBR diolah menggunakan metode grafis untuk mendapatkan nilai CBR 90\%. Nilai CBR ini merupakan nilai persentil ke 10, yang mengartikan bahwa terdapat 90\% dari data CBR pada segmen tersebut yang memiliki nilai lebih besar atau sama dengan nilai CBR pada persentil tersebut atau nilai CBR yang mewakili.

Berdasarkan Gambar 3, didapatkan nilai CBR tanah dasar yang mewakili yakni 22,7\%. Menurut Manual Desain Perkerasan Jalan (Dirjen Bina Marga, 2017), karena Nilai CBR yang didapat lebih dari atau sama dengan $6 \%$ maka tidak diperlukan perbaikan tebal pada tanah dasar. Pada perencanaan perkerasan kaku nilai CBR juga digunakan pada tahap analisi fatik dan erosi. 


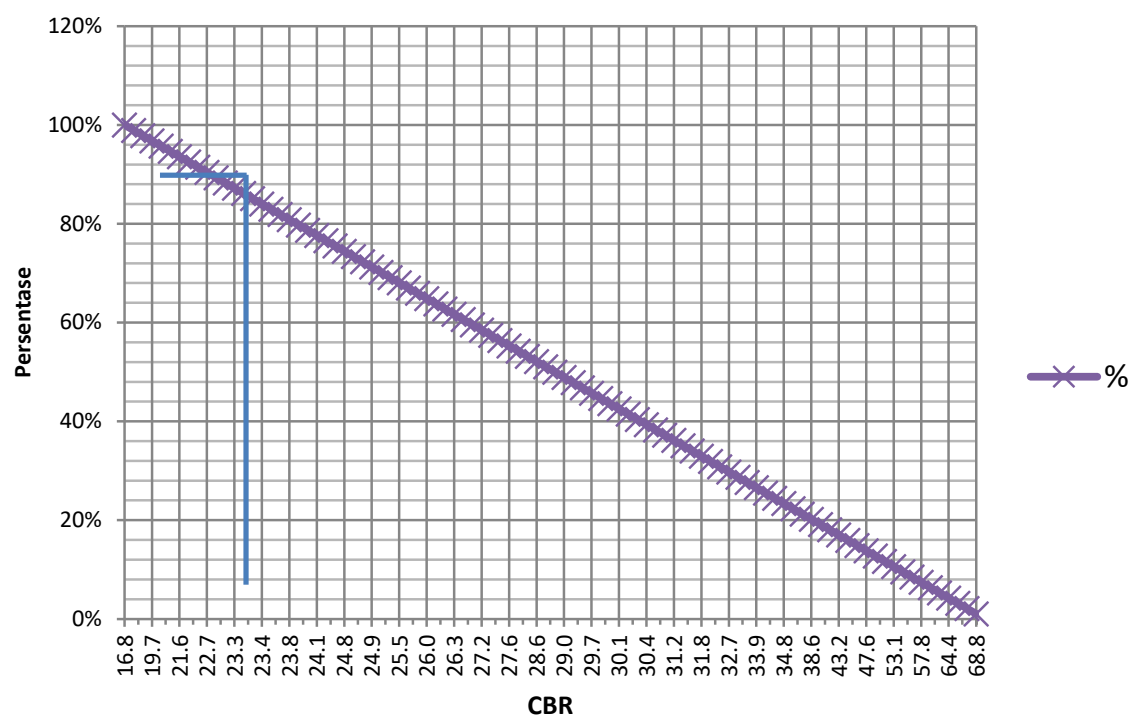

Gambar 3. CBR 90\%

\subsection{Volume Lalu lintas Harian Rata-Rata}

Volume lalu lintas diolah berdasarkan asal dan tujuan kendaraan yang diasumsikan akan melewati Jalan Lintas Selatan saat telah beroperasi. Data yang diperoleh dari beberapa jembatan timbang diproyeksikan ke tahun 2022 (tahun asumsi jalan telah beroperasi).

Tabel 1. Data LHR pada Tahun 2022

\begin{tabular}{ccccc}
\hline & \multicolumn{4}{c}{ VLHR } \\
\cline { 2 - 5 } Jenis Kendaraan & $\begin{array}{c}\text { JT } \\
\text { Sedaru } \\
\text { m }\end{array}$ & $\begin{array}{c}\text { JT } \\
\text { Rejoso }\end{array}$ & $\begin{array}{c}\text { JT Rambigundam } \\
\text { menuju Banyuwangi }\end{array}$ & $\begin{array}{c}\text { JT Rambigundam } \\
\text { menuju Surabaya }\end{array}$ \\
\hline Truk 1.2 L & 13 & 57 & 328 & 194 \\
\hline Truk 1.2 H & 6 & 17 & 72 & 51 \\
\hline Truk 1.22 & 1 & 2 & 42 & 49 \\
\hline Truk 1.2-2 & 0 & 1 & 31 & 3 \\
\hline Truk 1.2+2.2 & 0 & 0 & 24 &
\end{tabular}

Data yang digunakan merupakan data yang memiliki nilai LHR terbesar, karena diasumsikan menghasilkan beban lalu lintas yang paling besar pula. Berdasarkan Tabel $\mathbf{1}$, data yang digunakan untuk tahap selanjutnya ialah data dari Jembatan Timbang Rambigundam yang menuju Banyuwangi.

\subsection{3. Faktor Pertumbuhan Lalu Lintas}

Berdasarkan Manual Desain Perkerasan Jalan (Dirjen Bina Marga, 2017), didapatkan faktor pertumbuhan lalu lintas (i) di Pulau Jawa sebesar 4,8\%. Faktor ini digunakan untuk mendapatkan nilai faktor pertumbuhan lalu lintas (R). Nilai R untuk umur rencana 20 tahun $=32,38$ dan nilai $\mathrm{R}$ untuk umur rencana 40 tahun $=115,06$. 


\subsection{Penentuan Jenis Perkerasan}

Penentuan jenis perkerasan sesuai Manual Desain Perkerasan Jalan (Dirjen Bina Marga, 2017) ditentukan berdasarkan perhitungan kumulatif beban lalu lintas ( $\mathrm{CESA}^{4}$ ). Perhitungan beban lalu lintas menggunakan volume hasil analisis pada Tabel 1.

Tabel 2. Perhitungan Beban Lalu Lintas

\begin{tabular}{llll}
\hline Tipe Kendaraan & VLHR & VDF $^{4}$ & $\mathrm{ESA}^{4}$ \\
\hline $1.2 \mathrm{~L}$ & 328 & 0,3 & 580.822 \\
\hline $1.2 \mathrm{H}$ & 72 & 0,9 & 383.933 \\
\hline 1.22 & 42 & 7,6 & 1.870 .442 \\
\hline $1.2-2$ & 31 & 28,1 & 5.071 .524 \\
\hline $1.2+2.2$ & 24 & 36,9 & 5.146 .177 \\
\hline & & $\mathrm{CESA}^{4}$ & 13.052 .897 \\
\hline
\end{tabular}

Berdasarkan Tabel 2 didapatkan beban lalu lintas $>10-30$ juta. Berdasarkan Manual Desain Perkerasan Jalan, maka jenis perkerasan yang dapat digunakan ialah perkerasan kaku dengan lalu lintas berat (di atas tanah dengan $\mathrm{CBR} \geq 2,5 \%$ ) serta perkerasan lentur dengan asphalt concrete $(\mathrm{AC})$ tebal $\geq 100 \mathrm{~mm}$ dengan lapis pondasi berbutir.

\subsection{Perencanaan Perkerasan Lentur}

Perkerasan lentur direncanakan dengan umur rencana 20 tahun dan nilai life cycle cost 2 kali 20 tahun menggunakan nilai pertumbuhan lalu lintas $(R)=32,38$. Penentuan struktur perkerasan lentur didasarkan pada kumulatif beban lalu lintas $\left(\mathrm{CESA}^{5}\right)$. Hasil perhitungan beban lalu lintas ditampilkan pada Tabel 3 berikut.

Tabel 3. Perhitungan $\mathrm{ESA}^{5}$ umur rencana 20 tahun

\begin{tabular}{cccc}
\hline Tipe Kendaraan & VLHR & VDF $^{5}$ & ESA $^{5}$ \\
\hline $1.2 \mathrm{~L}$ & 328 & 0,2 & 387.214 \\
\hline $1.2 \mathrm{H}$ & 72 & 0,8 & 341.274 \\
\hline 1.22 & 42 & 11,2 & 2.756 .441 \\
\hline $1.2-2$ & 31 & 64,4 & 11.622 .994 \\
\hline $1.2+2.2$ & 24 & 90,4 & 12.607 .437 \\
\hline & & $\mathrm{CESA}^{5}$ & 15.107 .923 \\
\hline
\end{tabular}

Berdasarkan Tabel 3 didapatkan beban lalu lintas $>$ 10-20 juta. Berdasarkan Manual Desain Perkerasan Jalan (Dirjen Bina Marga, 2017), maka didapatkan ketebalan AC WC setebal 40 $\mathrm{mm}, \mathrm{AC}$ BC setebal $60 \mathrm{~mm}$, AC Base $145 \mathrm{~mm}$ dan LFA kelas A setebal $300 \mathrm{~mm}$. Karena, nilai CBR tanah dasar $\geq 7 \%$ maka LFA kelas A dapat disesuaikan menjadi $150 \mathrm{~mm}$. Kemudian dilakukan pengecekan tabel perkerasan yang telah diperoleh dengan pedoman Pt T-012002-B, sehingga dapat ditentukan W18=15.107.923; SO=0,45; IPO=4; IPt=2,5; IPf=1,5; $\triangle \mathrm{PSI}=1,5 ; \mathrm{Mr}=34.050 \mathrm{psi}$; dan $\mathrm{Zr}=-1,282$. Dari data tersebut dicari nilai Sn (Structural Number) menggunakan nomogram pada Pt T-01-2002-B dan didapatkan $\mathrm{Sn}=3,2$. Selanjutnya dicari nilai ITP, untuk menghitung ITP nilai D1 diambil dari tebal lapis permukaan $=245 \mathrm{~mm}=9,65$ inch dan D2 dari tebal $\mathrm{LFA}=150 \mathrm{~mm}=5,91$ inch. Nilai a1 dan a2 didapatkan dari grafik pada Pt T-01-2002-B. Didapat nilai ITP $=3,70>\mathrm{Sn}=3,2$; nilai ITP harus lebih besar daripada Sn, yang menandakan ketebalan yang direncanakan (ITP) telah mencukupi dari kebutuhan (Sn) yang diperlukan. Agar tebal perkerasan lebih efisien dan 
tidak boros, maka nilai ITP dibuat mendekati nilai Sn. Dicoba dengan ketebalan AC WC setebal $40 \mathrm{~mm}$, AC BC setebal $60 \mathrm{~mm}$, AC Base $115 \mathrm{~mm}$ dan LFA kelas A setebal $130 \mathrm{~mm}$. Dengan langkah yang sama, dicari nilai ITP dengan nilai D1 diambil dari tebal lapis permukaan $=215 \mathrm{~mm}=8,45$ inch dan D2 dari tebal $\mathrm{LFA}=130 \mathrm{~mm}=5,11$ inch. Nilai a1 dan a2 didapatkan dari grafik pada Pt T-01-2002-B. Didapat nilai ITP=3,23 > Sn=3,2. Sehingga, tebal perkerasan lentur dengan ketebalan AC WC setebal $40 \mathrm{~mm}, \mathrm{AC} \mathrm{BC}$ setebal $60 \mathrm{~mm}, \mathrm{AC}$ Base 115 mm dan LFA kelas A setebal 130 mm dapat digunakan.

\subsection{Perencanaan Perkerasan Kaku}

Perkerasan kaku direncenakan dengan umur rencana 40 tahun. Penentuan struktur perkerasan kaku ditentukan berdasarkan pada kumulatif repetisi sumbu (HVAG). Untuk mendapatkan kumulatif repetisi sumbu terlebih dahulu dilakukan analisis terhadap kelompok sumbu kendaraan niaga. Hasil analisis disajikan pada Tabel 4.

Tabel 4. Analisis Kelompok Sumbu Kendaraan Niaga

\begin{tabular}{|c|c|c|c|c|c|c|c|c|c|c|c|c|c|c|}
\hline \multirow{2}{*}{$\begin{array}{l}\mathrm{N} \\
\mathrm{o}\end{array}$} & \multirow{2}{*}{$\begin{array}{c}\text { Jenis } \\
\text { Kendara } \\
\text { an }\end{array}$} & \multicolumn{4}{|c|}{ Konfigurasi Beban Sumbu (ton) } & \multirow{2}{*}{$\begin{array}{c}\text { Jml } \\
\text { h } \\
\text { Ken } \\
\text { d } \\
\text { (bh) }\end{array}$} & \multirow{2}{*}{$\begin{array}{c}\text { Jml } \\
\text { h } \\
\text { Sum } \\
\text { bu / } \\
\text { Ken } \\
\text { d } \\
\text { (bh) } \\
\end{array}$} & \multirow{2}{*}{$\begin{array}{c}\text { Jml } \\
\text { h } \\
\text { Sum } \\
\text { bu } \\
\text { (bh) }\end{array}$} & \multicolumn{2}{|c|}{ STRT } & \multicolumn{2}{|c|}{ STRG } & \multicolumn{2}{|c|}{ STdRG } \\
\hline & & $\mathbf{R D}$ & RB & RGD & RGB & & & & $\begin{array}{c}\text { BS } \\
\text { (ton } \\
\text { ) }\end{array}$ & $\begin{array}{c}\text { JS } \\
\text { (bh) }\end{array}$ & $\begin{array}{l}\text { BS } \\
\text { (ton) }\end{array}$ & $\begin{array}{c}\text { JS } \\
\text { (bh) }\end{array}$ & $\begin{array}{c}\text { BS } \\
\text { (ton } \\
\text { ) }\end{array}$ & $\begin{array}{l}\text { JS } \\
\text { (b } \\
\text { h) }\end{array}$ \\
\hline \multirow[t]{2}{*}{1} & $\begin{array}{c}\text { Truk } 1.2 \\
\mathrm{~L}\end{array}$ & 2,8 & 5,48 & & & 328 & 2 & 656 & 2,82 & 328 & & & & \\
\hline & & & & & & & & & & & 5,48 & 328 & & \\
\hline \multirow[t]{2}{*}{2} & $\begin{array}{c}\text { Truk } 1.2 \\
\mathrm{H} \\
\end{array}$ & 6,2 & 12 & & & 72 & 2 & 144 & 6,19 & 72 & & & & \\
\hline & & & & & & & & & & & 12,01 & 72 & & \\
\hline \multirow[t]{2}{*}{3} & $\begin{array}{l}\text { Truk } \\
1.22 \\
\end{array}$ & 6,3 & 18,8 & & & 42 & 3 & 126 & 6,25 & 42 & & & & \\
\hline & & & & & & & & & & & & & 18,8 & 42 \\
\hline \multirow[t]{3}{*}{4} & $\begin{array}{l}\text { Truk } \\
1.2-2 \\
\end{array}$ & 4,7 & 10,7 & 10,74 & & 31 & 3 & 93 & 4,72 & 31 & & & & \\
\hline & & & & & & & & & & & 10,74 & 31 & & \\
\hline & & & & & & & & & & & 10,74 & 31 & & \\
\hline \multirow[t]{5}{*}{5} & $\begin{array}{c}\text { Truk } \\
1.2+2.2 \\
\end{array}$ & 5,7 & 8,79 & 8,478 & 8,478 & 24 & 4 & 96 & 5,65 & 24 & & & & \\
\hline & & & & & & & & & & & 8,79 & 24 & & \\
\hline & & & & & & & & & & & 8,48 & 24 & & \\
\hline & & & & & & & & & & & 8,48 & 24 & & \\
\hline & \multicolumn{5}{|c|}{ Total } & & & 1115 & & 496 & & 532 & & 42 \\
\hline
\end{tabular}

Pada Tabel 4 didapatkan jumlah sumbu kendaraan niaga harian (JSKNH) sebanyak 1.115 buah. Maka, dapat diperoleh jumlah sumbu kendaraan niaga (JSKN) selama umur rencana $=365 \times$ JSKNH $\times \mathrm{R}=46.826 .544$. Untuk mendapatkan nilai JSKN rencana perlu dikalikan dengan koefisien c (0,5 untuk tipe jalan 2/2 UD), sehingga didapat nilai JSKN selama umur rencana sebesar 23.413.272. Nilai JSKN selanjutnya digunakan untuk mendapatkan repetisi sumbu yang terjadi. 
Tabel 5. Repetisi Sumbu yang Terjadi

\begin{tabular}{ccccccc}
\hline $\begin{array}{c}\text { Jenis } \\
\text { Sumbu }\end{array}$ & $\begin{array}{c}\text { Beban } \\
\text { Sumbu }\end{array}$ & $\begin{array}{c}\text { Jumlah } \\
\text { Sumbu }\end{array}$ & $\begin{array}{c}\text { Proporsi } \\
\text { Beban }\end{array}$ & $\begin{array}{c}\text { Proporsi } \\
\text { Sumbu }\end{array}$ & $\begin{array}{c}\text { Lalu Lintas } \\
\text { Rencana }\end{array}$ & $\begin{array}{c}\text { Repetisi yang } \\
\text { Terjadi }\end{array}$ \\
\hline \multirow{2}{*}{ STRT } & 2,82 & 328 & 0,66 & 0,53 & 23.413 .272 & 8.185 .974 \\
& 6,19 & 72 & 0,15 & 0,53 & 23.413 .272 & 1.803 .689 \\
& 6,25 & 42 & 0,08 & 0,53 & 23.413 .272 & 1.040 .590 \\
& 4,72 & 31 & 0,06 & 0,53 & 23.413 .272 & 763.099 \\
& 5,65 & 24 & 0,05 & 0,53 & 23.413 .272 & 589.668 \\
\hline Total & & 496 & 1 & & & \\
\hline \multirow{2}{*}{ STRG } & 5,48 & 328 & 0,82 & 0,43 & 23.413 .272 & 8.185 .974 \\
& 12,01 & 72 & 0,18 & 0,43 & 23.413 .272 & 1.803 .689 \\
& 10,74 & 31 & 0,08 & 0,43 & 23.413 .272 & 763.099 \\
& 10,74 & 31 & 0,08 & 0,43 & 23.413 .272 & 763.099 \\
& 8,79 & 24 & 0,06 & 0,43 & 23.413 .272 & 589.668 \\
& 8,48 & 24 & 0,06 & 0,43 & 23.413 .272 & 589.668 \\
& 8,48 & 24 & 0,06 & 0,43 & 23.413 .272 & 589.668 \\
\hline Total & \multicolumn{7}{c}{400} & 1,00 & & & \\
\hline STdRG & 18,75 & 42 & 1,00 & 0,04 & 23.413 .272 & 1.040 .590 \\
\hline Total & \multicolumn{7}{c}{42} & 1,00 & & & \\
\hline Kumulatif & 937 & & & & 26.708 .473 \\
\hline
\end{tabular}

Pada Tabel 5 didapatkan kumulatif repetisi sumbu $<43$ juta, berdasarkan Manual Desain Perkerasan Jalan, untuk jalan dengan beban lalu lintas berat struktur perkerasan kaku yang dapat digunakan yakni tebal pelat beton $295 \mathrm{~mm}$, lapis pondasi Lean Mix Concrete (LMC) $100 \mathrm{~mm}$, dan lapis drainase $150 \mathrm{~mm}$. Dengan tie bars diameter $16 \mathrm{~mm}$ dan panjang $450 \mathrm{~mm}$ serta dowel diameter $36 \mathrm{~mm}$ (Saodang, 2005). Kemudian dilakukan pengecekan ketebalan terhadap fatik dan erosi dengan pedoman Pd T-14-2003. Berdasarkan Pedoman Perencanaan Perkerasan Jalan Beton (Departemen Permukiman dan Prasarana Wilayah, 2003), tebal pelat beton dapat digunakan apabila hasil analisis fatik dan erosi lebih kecil atau mendekati $100 \%$. Didapatkan hasil analisis fatik dan erosi sebesar $0 \%$, yang menandakan bahwa pelat beton mampu menahan terjadinya retak fatik tarik lentur pada pelat beton dan mampu menahan terjadinya erosi pada pondasi bawah atau tanah dasar, namun memiliki tebal pelat yang boros. Agar tebal perkerasan efisien dan tidak boros, direncanakan pelat beton dengan hasil analisis fatik dan erosi yang mendekati 100\%. Dicoba menggunakan pelat beton $195 \mathrm{~mm}, \mathrm{LMC} 100 \mathrm{~mm}$ dan lapis drainase $150 \mathrm{~mm}$ dengan hasil analisis fatik dan erosi tertera pada Tabel 6 .

Tabel 6. Analisis Fatik dan Erosi

\begin{tabular}{|c|c|c|c|c|c|c|c|c|c|c|}
\hline \multirow{2}{*}{$\begin{array}{l}\text { Jenis } \\
\text { Sumbu }\end{array}$} & \multicolumn{2}{|c|}{ Beban Sumbu } & \multirow{2}{*}{$\begin{array}{c}\text { Beban } \\
\text { Rencana } \\
\text { Per Roda } \\
(\mathrm{kN})\end{array}$} & \multirow{2}{*}{$\begin{array}{l}\text { Repetisi } \\
\text { yang } \\
\text { Terjadi }\end{array}$} & \multirow{2}{*}{\multicolumn{2}{|c|}{$\begin{array}{c}\text { Faktor } \\
\text { Tegangan Erosi }\end{array}$}} & \multicolumn{2}{|c|}{ Analisa Fanatik } & \multicolumn{2}{|c|}{ Analisa Erosi } \\
\hline & Ton & $\mathrm{kN}$ & & & & & $\begin{array}{c}\text { Repetisi } \\
\text { Ijin }\end{array}$ & $\begin{array}{c}\text { Persen } \\
\text { Rusak }\end{array}$ & Repetisi Ijin & $\begin{array}{c}\% \\
\text { Rusak }\end{array}$ \\
\hline \multirow[t]{5}{*}{ STRT } & 2,82 & 28,22 & 15,52 & $\begin{array}{c}8.185 .973,5 \\
3 \\
\end{array}$ & $\mathrm{TE}$ & 0,89 & $\mathrm{TT}$ & - & $\mathrm{TT}$ & - \\
\hline & 6,19 & 61,88 & 34,03 & $\begin{array}{c}1.803 .689 \\
08\end{array}$ & FRT & 0,20 & $\mathrm{TT}$ & - & $\mathrm{TT}$ & - \\
\hline & 6,25 & 62,50 & 34,38 & $\begin{array}{c}1.040 .589 \\
86\end{array}$ & $\mathrm{FE}$ & 1,78 & $\mathrm{TT}$ & - & TT & - \\
\hline & 4,72 & 47,16 & 25,94 & $763.099,23$ & & & TT & - & $\mathrm{TT}$ & - \\
\hline & 5,65 & 56,52 & 31,09 & $589.667,58$ & & & TT & - & $\mathrm{TT}$ & - \\
\hline
\end{tabular}


Perbandingan Life Cycle Cost Perkerasan Kaku dan Lentur

(Studi Kasus: Jalan Lintas Selatan Jarit-Puger STA 25+50O - STA 4O+40O)

\begin{tabular}{|c|c|c|c|c|c|c|c|c|c|c|}
\hline \multirow{2}{*}{$\begin{array}{l}\text { Jenis } \\
\text { Sumbu }\end{array}$} & \multicolumn{2}{|c|}{ Beban Sumbu } & \multirow{2}{*}{$\begin{array}{c}\text { Beban } \\
\text { Rencana } \\
\text { Per Roda } \\
(\mathrm{kN})\end{array}$} & \multirow{2}{*}{$\begin{array}{l}\text { Repetisi } \\
\text { yang } \\
\text { Terjadi }\end{array}$} & \multirow{2}{*}{\multicolumn{2}{|c|}{$\begin{array}{c}\text { Faktor } \\
\text { Tegangan Erosi }\end{array}$}} & \multicolumn{2}{|c|}{ Analisa Fanatik } & \multicolumn{2}{|c|}{ Analisa Erosi } \\
\hline & Ton & $\mathbf{k N}$ & & & & & $\begin{array}{c}\text { Repetisi } \\
\text { Ijin }\end{array}$ & $\begin{array}{l}\text { Persen } \\
\text { Rusak }\end{array}$ & Repetisi Ijin & $\begin{array}{c}\% \\
\text { Rusak }\end{array}$ \\
\hline \multirow[t]{7}{*}{ STRG } & 5,48 & 54,78 & 15,06 & $\begin{array}{c}8.185 .973,5 \\
3\end{array}$ & $\mathrm{TE}$ & 1,36 & $\mathrm{TT}$ & - & $\mathrm{TT}$ & - \\
\hline & 12,01 & 120,12 & 33,03 & $\begin{array}{c}1.803 .689 \\
08\end{array}$ & FRT & 0,30 & 2.000 .000 & 90,18 & 2.500 .000 & 72,15 \\
\hline & 10,74 & 107,42 & 29,54 & $763.099,23$ & $\mathrm{FE}$ & 2,38 & $\mathrm{TT}$ & - & 10.000 .000 & 7,63 \\
\hline & 10,74 & 107,42 & 29,54 & $763.099,23$ & & & TT & - & 10.000 .000 & 7,63 \\
\hline & 8,79 & 87,92 & 24,18 & $589.667,58$ & & & $\mathrm{TT}$ & - & $\mathrm{TT}$ & - \\
\hline & 8,48 & 84,78 & 23,31 & $589.667,58$ & & & TT & - & $\mathrm{TT}$ & - \\
\hline & 8,48 & 84,78 & 23,31 & $589.667,58$ & & & $\mathrm{TT}$ & - & TT & - \\
\hline \multirow[t]{4}{*}{ STdRG } & 18,75 & 187,50 & 4,30 & $\begin{array}{c}1.040 .589 \\
86 \\
\end{array}$ & $\mathrm{TE}$ & 1,14 & $\mathrm{TT}$ & - & $\mathrm{TT}$ & - \\
\hline & & & & & FRT & 0,25 & & & & \\
\hline & & & & & $\mathrm{FE}$ & 2,43 & & & & \\
\hline & & & & & & & $\begin{array}{c}\sum \text { Analisis } \\
\text { Fatik }\end{array}$ & 90,18 & $\begin{array}{c}\sum \text { Analisis } \\
\text { Erosi }\end{array}$ & 87,41 \\
\hline
\end{tabular}

Berdasarkan hasil analisis pada Tabel 6, didapatkan hasil analisis fatik dan erosi telah mendekati $100 \%$ yang menandakan bahwa selama umur rencana pelat beton diasumsikan mampu menahan terjadinya retak fatik pada pelat beton hingga kerusakan 90,18\% dan mampu menahan terjadinya erosi pada pondasi bawah hingga kerusakan $87,41 \%$. Maka, tebal pelat beton $195 \mathrm{~mm}$ dianggap memiliki ketebalan paling efisien dan memenuhi syarat sebagai perkerasan kaku.

\subsection{Perhitungan nilai Life Cycle Cost}

\subsubsection{Perhitungan RAB}

Dengan mengalikan volume perkerasan dengan AHSP Provinsi Jawa Timur didapatkan biaya awal konstruksi perkerasan lentur senilai Rp65.904.024.116 dan perkerasan kaku senilai Rp59.728.962.641. Didapatkan biaya konstruksi perkerasan lentur lebih mahal dibanding perkerasan kaku. Hal ini disebabkan karena perkerasan lentur memiliki lapisan lebih banyak yakni LPA, AC Base, lapis resap pengikat/prime coat, $\mathrm{AC} \mathrm{BC}$, lapis perekat/tack coat dan AC WC sedangkan perkerasan kaku hanya terdiri atas lapisan drainase, LMC dan pelat beton.

\subsubsection{Perhitungan Life Cycle Cost}

Nilai life cycle cost didapatkan dari penjumlahan biaya konstruksi dan biaya pemeliharaan di masa yang akan datang selama umur rencana. Asumsi kebutuhan biaya permeliharaan perkerasan lentur dan kaku didapatkan dari perhitungan biaya pada Jalan Kabupaten Demak Indramayu oleh PT. Blantickindo Aneka. Didapatkan biaya pemeliharaan untuk setiap jenis perkerasan adalah sebagai berikut:

- Perkerasan Lentur

Pada perkerasan lentur pemeliharaan jalan terdiri atas pemeliharaan rutin setiap 1 tahun sekali, pemeliharaan berkala setiap 5 tahun sekali dan rekonstruksi setiap 15 tahun sekali. Diasumsikan pemeliharaan rutin membutuhkan biaya sebesar 2,3\% dari total biaya konstruksi. Pemeliharaan berkala meliputi pelapisan ulang (overlay) satu lapis AC-WC setebal $4 \mathrm{~cm}$ selebar dan sepanjang jalan, diasumsikan membutuhkan biaya jumlah 
harga AC-WC dan lapis perekat/tack coat. Sedangkan rekontruksi diasumsikan dilakukan pada lapis AC-WC, AC-BC dan AC Base.

- Perkerasan Kaku

Pada perkerasan kaku hanya dilakukan pemeliharaan rutin setiap 1 tahun sekali dan pemeliharaan berkali setiap 10 tahun sekali. Hal ini disebabkan perkerasan kaku cenderung membutuhkan pemeliharaan yang minimum. Pemeliharaan rutin meliputi pengisian celah atau retak permukaan (sealing) diasumsikan membutuhkan biaya sebesar $0,39 \%$ dari total biaya konstruksi. Pemeliharaan berkala meliputi pengisian celah atau retak permukaan maupun partial depth repair yang diasumsikan sebesar $42,4 \%$ dari total biaya konstruksi.

Tabel 7. Perbandingan Tiap Jenis Perkerasan

\begin{tabular}{lcc}
\hline & Perkerasan Lentur & Perkerasan Kaku \\
\hline Konstruksi & Rp65.904.024.116 & Rp59.728.962.641 \\
\hline Pemeliharaan Rutin & Rp1.515.792.555 & Rp232.942.954 \\
Pemeliharaan Berkala & Rp10.777.124.777 & Rp25.325.080.160 \\
Rekontruksi & Rp52.137.904.138 & - \\
\hline
\end{tabular}

Berdasarkan Manual Desain Perkerasan Jalan, perkerasan kaku direncanakan dengan umur rencana 40 tahun, sehingga didapat nilai life cycle cost sebesar Rp169.415.229.636. Sedangkan perkerasan lentur lapisan aspal direncanakan dengan umur rencana 20 tahun. Agar sebanding dengan perkerasan kaku, maka nilai life cycle cost perkerasan lentur perlu diasumsikan dua kali umur rencana, sehingga didapatkan nilai sebesar Rp349.251.966.920.

\subsubsection{Perhitungan Discounted Life Cycle Cost}

Discounted life cycle cost perkerasan jalan diperoleh dengan cara menjumlahkan biaya konstruksi dan biaya pemeliharaan yang telah dihitung nilai futurenya menggunakan tingkat nilai inflasi Indonesia sejak 2019 sampai dengan 2020 yakni sebesar 2,67\% dengan rumus 3, kemudian nilai tadi dipresent kembali menggunakan suku bunga Indonesia sejak 2019 sampai dengan 2020 sebesar 5,05\% dengan rumus 4. Sehingga, didapatkan nilai discounted life cycle cost perkerasan kaku selama umur rencana 40 tahun sebesar Rp64.501.092.789. Agar sebanding dengan perkerasan kaku, maka nilai discounted life cycle cost perkerasan lentur perlu diasumsikan dua kali umur rencana, sehingga nilai discounted life cycle cost perkerasan lentur selama umur rencana sebesar Rp162.834.408.862.

Tabel 8. Perbandingan Tiap Jenis Perkerasan

\begin{tabular}{lcc}
\hline \multicolumn{1}{c}{ Biaya } & Perkerasan Lentur & Perkerasan Kaku \\
\hline Life Cycle Cost & Rp349.251.966.920 & Rp169.415.229.636 \\
Discounted Life Cycle Cost & Rp162.834.408.862 & Rp64.501.092.789 \\
\hline
\end{tabular}

Berdasarkan Tabel 8, dapat disimpulkan bahwa selama umur rencana 40 tahun, biaya yang dibutuhkan perkerasan lentur lebih besar dibanding perkerasan kaku. Ditinjau dari perbedaan biaya konstruksi, penelitian ini menghasilkan hasil yang sama dengan penelitian terdahulu yang mengatakan biaya konstruksi perkerasan lentur lebih mahal daripada perkerasan kaku (Nurahmi \& Kartika, 2012). Hal ini terjadi karena perkerasan lentur memiliki lebih banyak lapisan daripada perkerasan kaku. Menurut Suryaman (2016), kekuatan perkerasan pada perkerasan lentur diperoleh dari tebal masing-masing lapisannya. Karena modulus elastis/kekakuan perkerasan lentur cenderung lebih rendah daripada perkerasan kaku, maka dibutuhkan kekuatan yang tinggi pada masing-masing lapisan untuk mendistribusikan tegangan dari beban roda dan menyebarkan kelapisan bawahnya. Namun, 
penelitian ini memiliki hasil yang berbeda dengan penelitian lain yang mengatakan bahwa perkerasan kaku memiliki biaya konstruksi lebih mahal daripada perkerasan lentur (Satria, 2016). Perbedaan ini terjadi karena peneliti tidak memasukkan biaya untuk kebutuhan lapis resap pengikat/prime coat dan lapis perekat/tack coat pada perhitungan biaya konstruksi perkerasan lentur. Sehingga, mengakibatkan biaya konstruksi kaku menjadi lebih mahal. Ditinjau dari biaya pemeliharaan, perkerasan lentur juga cenderung memiliki lebih banyak tahapan pemeliharaan jalan dengan periode waktu yang lebih sering daripada perkerasan kaku. Berdasarkan konsep daasar konstruksi perkerasan kaku oleh Kementerian PUPR (Kementrian PUPR, 2017), hal ini terjadi karena perkerasan kaku mempunyai modulus elastis/kekauan jauh lebih tinggi daripada perkerasan lentur. Dengan modulus elastis yang lebih besar, perkerasan kaku mampu menyebarkan beban yang lebih tinggi daripada perkerasan lentur, sehingga lendutan yang terjadi lebih kecil. Oleh karena itu, perkerasan kaku cenderung membutuhkan pemeliharaan yang minimum. Akibatnya, perkerasan kaku memiliki nilai discounted life cycle cost lebih rendah dibandingkan perkerasan lentur (Wahidaturrohmah et al., 2019). Namun, memiliki hasil yang berbeda dengan penelitian lain yang mengatakan bahwa nilai discounted life cycle cost perkerasan kaku lebih mahal daripada perkerasan lentur (Betamal, 2015). Perbedaan tersebut disebabkan oleh biaya pemeliharaan yang mahal dikarenakan risiko ditanggung oleh kontraktor pada kontrak berbasis kinerja. Oleh karena itu, nilai life cycle cost untuk perkerasan lentur maupun kaku di setiap proyek tidak akan sama.

\section{KESIMPULAN}

Berdasarkan hasil perencanaan setiap jenis perkerasan dan perhitungan biaya yang dibutuhkan selama umur rencana, maka dapat diambil kesimpulan berikut:

1. Hasil ketebalan perkerasan untuk setiap jenis perkerasan didapatkan struktur perkerasan lentur terdiri atas lapis pondasi agregat kelas A $130 \mathrm{~mm}$, AC Base $115 \mathrm{~mm}$, AC BC $60 \mathrm{~mm}$ dan AC WC $40 \mathrm{~mm}$, sedangkan struktur perkerasan kaku terdiri dari lapisan drainase $150 \mathrm{~mm}$, LMC $100 \mathrm{~mm}$, dan pelat beton $195 \mathrm{~mm}$ dengan tie bars diameter $16 \mathrm{~mm}$ serta dowel diameter $36 \mathrm{~mm}$.

2. Hasil perhitungan nilai discounted life cycle cost selama umur rencana untuk perkerasan lentur senilai Rp162.834.408.862 dan perkerasan kaku senilai Rp64.501.092.789. Maka, dapat disimpulkan perkerasan lentur membutuhkan biaya 2,5 kali lebih banyak daripada perkerasan kaku. Perbedaan biaya disebabkan karena beberapa faktor, yakni perkerasan lentur cenderung memiliki lebih banyak lapisan yang mengakibatkan biaya konstruksi menjadi lebih mahal serta jenis pemeliharaan jalan selama umur rencana pada perkerasan lentur lebih banyak dan memiliki periode waktu yang lebih sering daripada perkerasan kaku, sehingga membutuhkan biaya pemeliharan yang lebih mahal. Maka dapat disimpulkan perkerasan kaku merupakan perkerasan yang paling efisien digunakan di lokasi proyek ini.

\section{DAFTAR PUSTAKA}

Betamal, F. N. (2015). Analisa Life Cycle Cost Perkerasan Kaku Dan Lentur Jalan Nasional (Studi Kasus: Jalan Batas Kota Bojonegoro-Padangan). Disertasi. Institut Teknologi Sepuluh Nopember.

Departemen Permukiman dan Prasarana Wilayah. (2003). Pd T-14-2003 : Perencanaan Perkerasan Jalan Beton Semen.

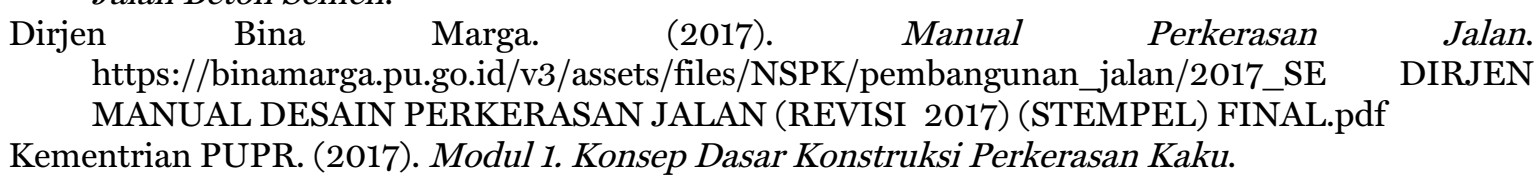


Nurahmi, O., \& Kartika, A. A. G. (2012). Perbandingan Konstruksi Perkerasan Lentur dan Perkerasan Kaku serta Analisis Ekonominya pada Proyek Pembangunan Jalan Lingkar Mojoagung. Jurnal Teknik ITS, 1(1), E63-E68.

Prayogo, A., Suprayitno, H., \& Budianto, H. (2018). Penentuan Kriteria Dalam Pemilihan Jenis Perkerasan Pada Dataran Tinggi Di Kabupaten Trenggalek. Journal of Civil Engineering, 33(1), 27. https://doi.org/10.12962/j20861206.v33i1.4565

Saodang, H. (2005). Konstruksi Jalan Raya. Bandung: Nova.

Satria, R. A. (2016). Studi Analisa Perbandingan Perkerasan Lentur dengan Perkerasan Kaku pada Ruas Jalan Ajung Kabupaten Jember. Universitas Muhammadiyah Jember.

Suryaman, D. (2016). Perbandingan Perencanaan Perkerasan Kaku Dan Perkerasan Lentur Menurut Metode Aashto Pada Jalan Teuku Iskandar Daod Area Kampus Utu Kabupaten Aceh Barat. Disertasi, Universitas Teuku Umar Meulaboh.

Wahidaturrohmah, K., Hasanuddin, A., \& Kriswardhana, W. (2019). Perencanaan Tebal Perkerasan pada Ruas Jalan Tol Gempol - Pasuruan STA 13+900 sampai dengan STA 20+500 dengan Metode Manual Desain Perkerasan Jalan Tahun 2017. Jurnal Rekayasa Sipil Dan Lingkungan, 3(1), 93-103. 